\title{
EXTREME SCENARIOS AT THE GERMAN NORTH SEA COAST A NUMERICAL MODEL STUDY
}

\author{
Gerd Bruss $^{1}$, Gabriele Gönnert ${ }^{2}$ and Roberto Mayerle ${ }^{1}$
}

\begin{abstract}
A procedure, based on numerical models is proposed to investigate the processes involved during conditions of extreme water levels within the outer Elbe estuary at the German North Sea coast. Nonlinear interactions between the different processes are analyzed and adverse combinations are simulated yielding new scenarios. Various conditions in the astronomical tide, three major storm events over the North Sea, several external surges and an increase in the mean sea level are analyzed. Techniques for the modeling of each of the isolated processes are developed and individually verified. The isolated processes are temporally shifted relative to each other and superimposed in various combinations. The results obtained from the present method, provide new insights into the nonlinear interactions between the involved processes. Generally, the effects of the processes seem to be reduced in superpositions with high absolute water levels. However, due to the large scatter of the results no general relations are found. New extreme scenarios are determined by iterative maximizations of the peak water level of different superpositions around spring high tide.
\end{abstract}

Keywords: North Sea; Hamburg; water level; storm surge; external surge; tide; mean sea level; nonlinear interactions; adverse superposition; extreme scenarios

\section{INTRODUCTION}

The most relevant processes contributing to significant water level variations at the German North Sea coast are the tides, wind surges generated by storms over the North Sea and external surges, generated on the Northeast Atlantic (Siefert, 1998, Gönnert, 1999, 2003). If these processes occur in adverse combinations their effects might accumulate to scenarios of extremely high water levels.

The aim of this study is to provide new insights into the nonlinear interactions beween the different processes and to determine adverse process combinations. The investigations are carried out using process based numerical models and thus complement the concurrent empirical analysis of the nonlinear superposition of extreme events (Gönnert et al., 2010a \& b). In empirical methods it is difficult to clearly identify the nature of the involved interactions. With the advancements in the field of numerical modeling, the water levels during extreme weather conditions can nowadays be reproduced rather well. Past storms can be reconstructed and the relative importance of the individual contributions leading to high water levels can be estimated. Deterministic models account for nonlinearities in the interactions between the involved processes and are therefore suitable tools to investigate these interactions and to simulate adverse process combinations, yielding extreme and consistent scenarios.

An existing modeling system, covering the entire North Sea and parts of the Northeast Atlantic, has been modified to cope with the requirements of the task. The extensive verification of the original model is described by Mayerle et al., 2005, confirming its adequacy in hindcasting water levels for a wide range of conditions typical to the site in question. This study is focused on the Station of Cuxhaven located at the mouth of the Elbe estuary. Techniques for the isolated modeling of each of the contributing processes are developed and verified. To investigate the mutual interactions, the processes are overlaid in various combinations. The most adverse superpositions lead to new scenarios of extreme water levels. The effects of an increase in the regional mean sea level on the local water level in Cuxhaven and its interaction with the other processes are also analyzed.

\section{AREA OF INTEREST AND MODEL SYSTEM}

The area of investigation is the German North Sea coast with focus on the conditions at the Station of Cuxhaven located at the mouth of the Elbe River some 100km from Hamburg (Fig.1). In order to capture the large scale processes, that are responsible for significant water level changes in Cuxhaven, an existing model system covering the North Sea and parts of the Northeast Atlantic is used. Fig. 1 shows the spatial coverage of the applied downscaling scheme of the depth-integrated flow models. The modeling system is based on the Delft3D software due to Delft Hydraulics (Lesser et al., 2004) and consists of 3 sequentially nested models in two different resolutions.

\footnotetext{
${ }_{2}^{1}$ Research and Technology Centre Westcoast, University of Kiel, Otto-Hahn-Platz 3, 24118 Kiel, Germany

${ }^{2}$ Hamburg Agency of roads, bridges and waters, Sachsenkamp 1-3, 20097 Hamburg, Germany
} 


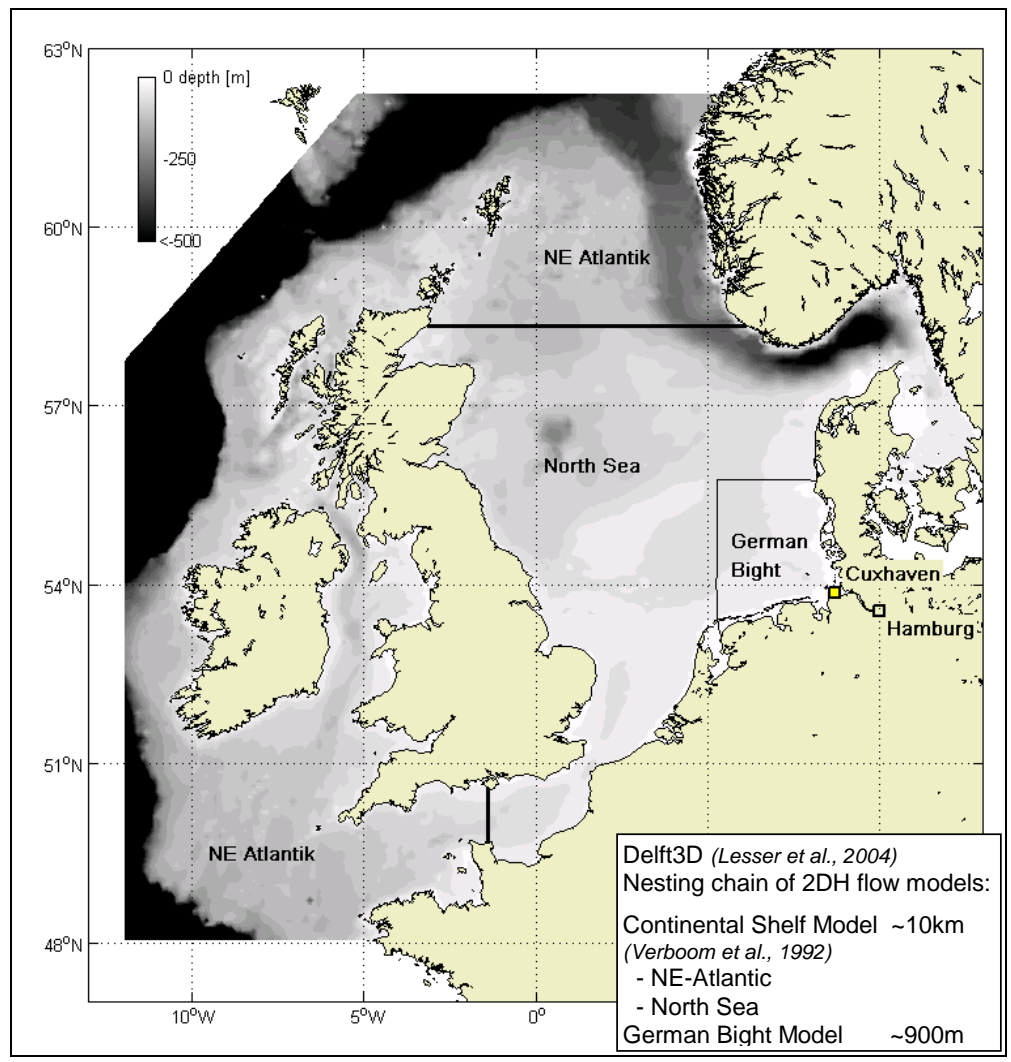

Fig. 1. Investigation area and model domains

The two larger models of the North Sea and the Northeast Atlantic have the same resolution of around $10 \mathrm{~km}$ and are based on an enhanced version of the Continental Shelf Model (CSM), set up by Verboom et al. (1992). The original CSM was split to enable simulations of the isolated effects of storm and external surges and to overlay them. Storm surges over the North Sea are modeled with the North Sea Model whereas external surges are simulated in the NE-Atlantic Model and passed as boundary conditions to the North Sea model. The German Bight model (GBM) is nested in the North Sea Model to increase the resolution along the German coastline to around $1 \mathrm{~km}$. The original nesting sequence of Continental Shelf and German Bight models has been validated extensively elsewhere (Mayerle et al., 2005). The verifications of the isolated process simulations performed in this study are described in the corresponding paragraphs below.

\section{METHOD}

The most relevant processes contributing to significant water level variations within the outer Elbe estuary are tides, surges generated by storm events over the North Sea and surges originated in the Northeast Atlantic, called external surges (Gönnert, 2003). The influence of the Elbe river discharge is negligible in the outer parts of the estuary (Rudolph, 2005). In other words extremely high water levels on the German North Sea coast are always caused by an adverse combination of tides and surges. In this study the different contributing processes are decoupled, modeled individually and superimposed in variable combinations. The investigations cover representative tidal conditions, three major storm events over the North Sea, several external surges formed on the Northeast Atlantic and an increase in the mean sea level due to global warming. The modification of the existing CSM was done in a way to allow for simulations of individual processes and for a flexible overlay of different process combinations. All model based realizations of single processes are verified individually by comparison with measurements, empirical data or astronomic tide predictions. The peaks of wind set up and external surges are temporally shifted and overlaid with the tide. Simulations with different combinations of processes are used to analyze the nature of their mutual interactions. Due to the nonlinearity of the interactions between the processes most adverse superpositions are obtained by 
iterating the temporal shifts around an average spring high tide. Extreme scenarios are simulated with and without the effects of an increased mean sea level.

In the following, the different techniques of modeling individual processes and the verification of each of the corresponding modeling techniques are described. Then the interactions of each process with the tide and the interactions between all processes are discussed. Finally the iterative approach leading to scenarios of high water levels is presented and the most extreme scenarios are compared to the recorded events.

\section{MODELING OF INDIVIDUAL PROCESSES}

\section{Astronomical tide}

The semidiurnal tide $(\sim 12.5 \mathrm{~h})$ of the North Sea has nowadays a mean amplitude of $\sim 3 \mathrm{~m}$ in Cuxhaven. The mean high tide is around $1.5 \mathrm{~m}$ above German datum (NN) with an increase of up to $0.6 \mathrm{~m}$ during spring tide. For the modeling of the pure tide, astronomical forcing, in the form of 10 spatially variable harmonic constituents, is applied along the open sea boundaries of the NE Atlantic model (Fig.2). No transfer of momentum from the atmosphere is considered. In this way the pure tide is modeled for the entire year of 1999. In the left hand side of Fig. 2 the performance of the model is verified by comparing the simulated high and low tides with astronomic predictions of the Federal Maritime and Hydrographic Agency of Germany (BSH) for the station of Cuxhaven. The coefficients of the linear fit and the standard deviation of the differences represent a good model performance. Out of the modeled year of 1999 one representative tidal period was selected as it includes the local tidal conditions of mean low tide $(-1.5 \mathrm{mNN})$, mean high tide $(1.5 \mathrm{mNN})$ and an average spring high tide (1.85mNN). This "average tide" of 14. August 1999 (c.f. Fig.5-7) is used throughout the further study to analyze the superpositions with the other processes.

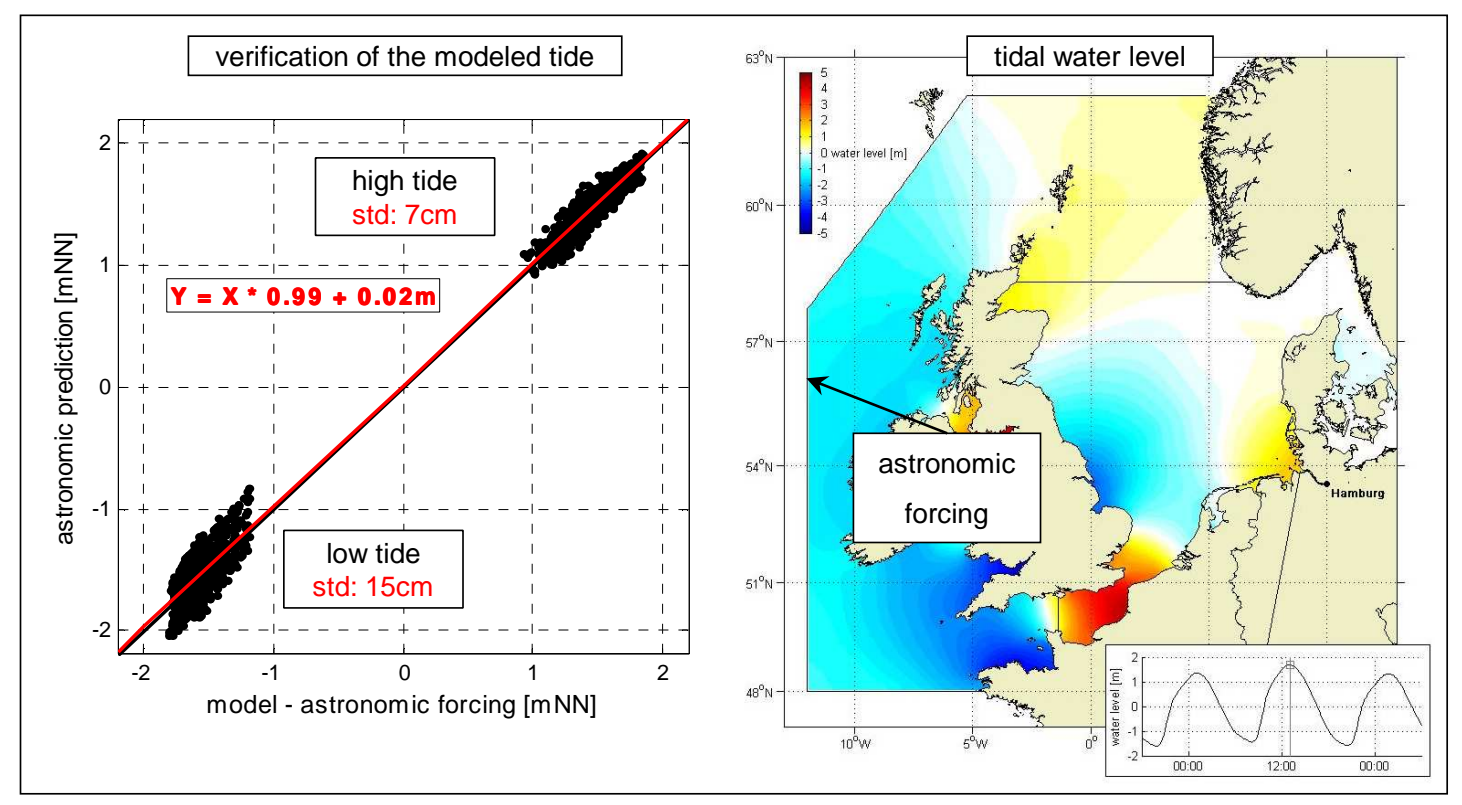

Fig. 2. Simulation and verification of the pure tide

\section{Increase in the mean sea level (MSL)}

There are different predictions for the increase of the mean seal level (MSL) due to global warming within the $21^{\text {rst }}$ century (Meehl et al., 2007). In this study the effects of an increase of the mean sea level of $0.5 \mathrm{~m}$ and $1 \mathrm{~m}$ are investigated, covering roughly the mean and the upper limit of the predictions. The simulations of an increased MSL are done by adding a constant value $(0.5 \mathrm{~m}$ or $1 \mathrm{~m})$ to the MSL of the open sea boundaries of the Northeast Atlantic model. The increase of the MSL is assumed as spatially constant along the open boundary sections. Since only extreme events during short periods of time are analyzed here, the MSL is considered to be temporally constant throughout the simulations. 


\section{Storm surges}

Storm surges at the southeastern German North Sea coast are produced by strong winds $(>25 \mathrm{~m} / \mathrm{s})$ over the North Sea with a prevailing direction between North and West (Jensen \& Müller-Navarra, 2008). Storm surges can be strongly variable both, in duration and peak water level, depending on the triggering meteorological situation (e.g. prolonged strong winds with constant direction or small fast moving intense low-pressure cyclones).

Recorded surges at Cuxhaven range up to $4.3 \mathrm{~m}$ during low tide and $3.7 \mathrm{~m}$ during high tide. Three relevant storm events, leading to significant surges at Cuxhaven, are focused on: the event of Feb. 1967, with the highest recorded surge (occurring at low tide), the event of Jan. 1976 with the highest measured absolute water level when the peak of the surge occurred close to high tide and the more recent storm of Dec. 1999. To reproduce the hydrodynamic situation of each storm the available data repository of meteorological hind casts from different sources is screened for suitable sets. After simulating the water levels with all available data sets the most suitable ones for the reproduction of the storm surges in Cuxhaven are selected. The best weather scenarios for the two earlier storms are identified among the meteorological ensembles, generated in the MUSE project (Koziar \& Renner, 2005). The more recent lesser storm surge of Dec. 1999 could be best reproduced using data from the PRISMA dataset (Luthardt, 1987). Fig. 3 shows the verification of the three hydrodynamic storm reproductions.

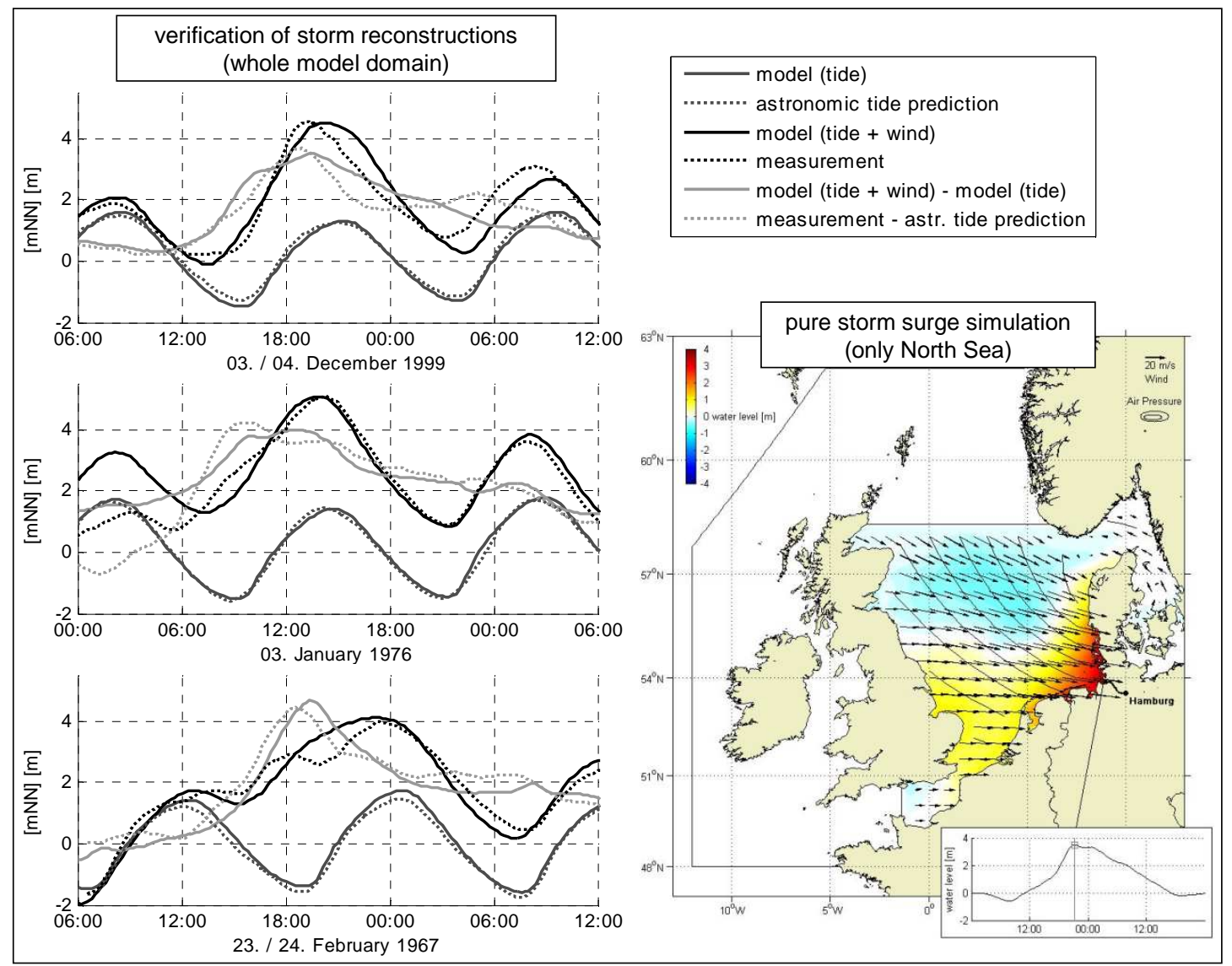

Fig. 3. Verification of the hydrodynamic storm reconstructions for the station Cuxhaven and sketch (lower right) of the technique of simulating isolated storm surges in the North Sea

First the pure astronomical tide was simulated for each period. The black lines (dotted and solid) show the simulated and the astronomically predicted tide at Cuxhaven. The agreement between modeled and astronomically predicted tidal water levels at the Station Cuxhaven is good for the periods in 1999 and 1976. The reconstruction of the tide in 1967 shows a certain vertical offset. This might be caused by differences between the implemented model bathymetry and the actual bathymetry in 1967 . 
To ensure comparability, all simulations are done with the same model bathymetry which is based on a data compilation around the year 2000.

The storm events are then simulated by driving the entire model system $(\mathrm{CSM}+\mathrm{GBM})$ with the selected meteorological data sets and the tide. The blue lines in Fig. 3 show the comparison of the measured and simulated water levels in Cuxhaven. The red lines represent the surges, determined as difference between absolute water level (blue) and tide (black). At the beginning of the ' 76 storm and after the peak of the ' 99 storm the simulated surges deviate from the observations (measurements - astr. pred.). Nevertheless, considering that the used meteorological data sets are not validated reanalysis of the events but rather selected as 'best suitable' from the available data repository, the overall hydrodynamic reconstructions of the storm events can be regarded as satisfactory. As will be seen later, it is important to notice, that the three storm surges are of significant differences both, in their peaks and in their temporal course.

Observed surges are determined as difference between measured water level and astronomically predicted tide and may contain the effects of external surges. For the next steps of this study pure storm surges are modeled individually only depending on the meteorological condition within the North Sea. The isolated modeling of storm surges is simulated by applying the transfer of momentum from the atmosphere only within the domain of the North Sea model (spatial plot in Fig.3). In simulations were effects entering from outside (tides, external surges) are superimposed with storm surges, these effects are introduced via the boundary conditions at the open boundaries of the North Sea model.

\section{External surges}

Another process which can contribute to a considerable increase in the near shore water levels at the German North Sea coast is the so called "external surge". External surges are disturbances to the water level, generated by meteorological impact outside the North Sea. In the deep waters of the North Atlantic such disturbances are mainly induced by fast moving systems of strong air pressure gradients. Over the shallower waters of the continental shelf the influence of the wind becomes predominant (Bork \& Müller-Navarra, 2006). External surges enter the North Sea as long waves, mostly through the northern boundary between Scotland and Norway and propagate inside the North Sea comparable to the tides, however with smaller amplitude. Their average travel time between northern Scotland and the mouth of the Elbe River is around 13 hours (Gönnert, 2003).

To identify external surges from records of water levels, the effects of tides and surges driven by wind within the North Sea have to be filtered out. In the case of the tides, astronomical predictions are subtracted from the measurements. To eliminate wind driven surges empirical relationships between measured wind and recorded surges are used (Müller-Navarra \& Giese, 1999). In this way several external surges of up to $\sim 1.1 \mathrm{~m}$ amplitude have been identified in Cuxhaven for the 24 years period between 1971 and 1995 (Gönnert, 2003). Based on this data several surges have been selected for the verification of the model based realization of this process.

Isolated external surges are simulated by imposing meteorological hind casts of the PRISMA dataset (Luthardt, 1987) over the NE-Atlantic for the periods of the selected surges. The wave, generated in the NE-Atlantic, is allowed to propagate freely within the North Sea with no further transfer of momentum from the atmosphere (spatial plot in Fig.4). On the left side of Fig. 4 three simulated surges are compared exemplary to the observed data at the stations Aberdeen and Cuxhaven. The observed surges at both stations are derived from water level measurements by the abovementioned filtering process.

Several uncertainties are involved in the verification of the applied technique. There are uncertainties in the empirical determination of external surges, uncertainties about the accuracy of the meteorological hind casts and about the influence of the model extent into the North Atlantic. Nevertheless the travel time of the surge between Aberdeen and Cuxhaven is reproduced and the shape and peak of the surges show a good agreement with the observations as well. This confirms the validity and robustness of the applied technique despite all uncertainties. The highest modeled external surge of December 1990 is selected for the further investigations. 


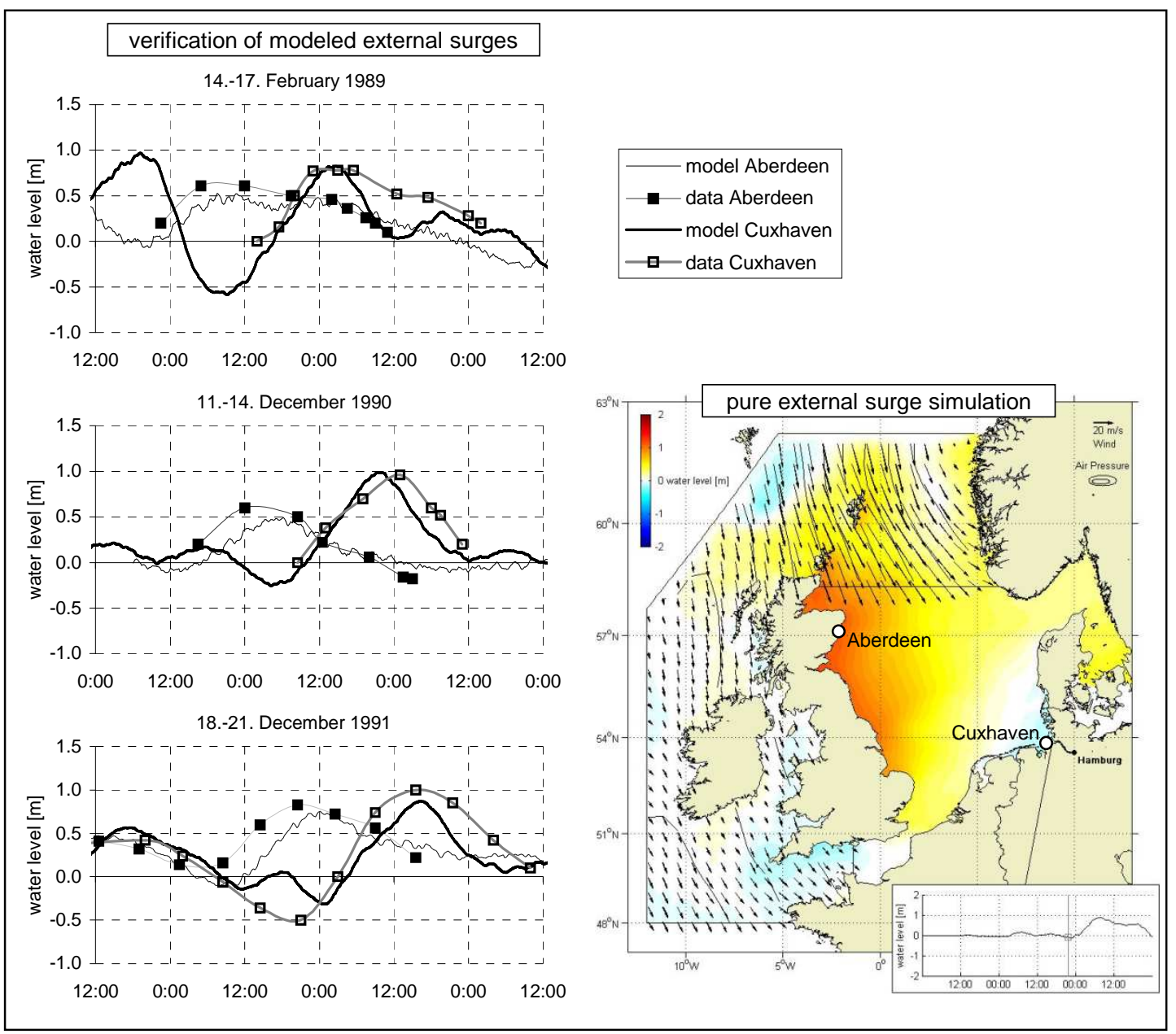

Fig. 4. Verification (left) and sketch (right) of the modeling technique for simulating isolated external surges

\section{INTERACTIONS WITH TIDE}

Each of the above described individual processes are superimposed with the tide and the resulting water levels at Cuxhaven are analysed to identify the nature of the interactions.

\section{Increased mean sea level (MSL)}

To investigate the effects of an increased mean sea level (MSL), the entire year of 1999 was simulated applying a MSL of $0 \mathrm{mNN}, 0.5 \mathrm{mNN}$ and $1 \mathrm{mNN}$. An increase in the MSL, modeled by raising the water levels at the open model boundaries in the Northeast Atlantic by a constant value, does not lead to a constant increase of the near shore water level at the German coast.

The top of Fig. 5 shows the three simulated time series of the water level in Cuxhaven for four days around the representative tide in Aug.' 99 and the differences with respect to the simulation with MSL $0 \mathrm{~m}$ (y-axis on the right). In the lower panel the differences are plotted against the tidal water level of MSL 0m for the entire year of 1999. The differences are not constant and the variation is moreover larger for a higher MSL. The increase of the local water level ranges between $\sim 0.4 \mathrm{~m}$ and $\sim 0.6 \mathrm{~m}$ for a MSL of $0.5 \mathrm{~m}$ and between $\sim 0.75 \mathrm{~m}$ and $\sim 1.25 \mathrm{~m}$ for a MSL of $1 \mathrm{~m}$. There is always a short peak at the beginning of the flood phase indicating the interaction with the tidal phase. At low tide the increase is always below the mean whereas at high tide it is above (black dots in Fig. 5). This means, that the local tidal amplitude gets larger. For a MSL of $0.5 \mathrm{~m}$ the highest rise of the local water level at Cuxhaven occurs close to high tide.

The tendency of a local increase in the amplitude accompanying a rise of the MSL is confirmed by the analysis of long term measurements of the water level at Cuxhaven. A stronger rise of the mean high tide compared to the increase of the mean low tide is observed (Mudersbach \& Jensen, 2006). 


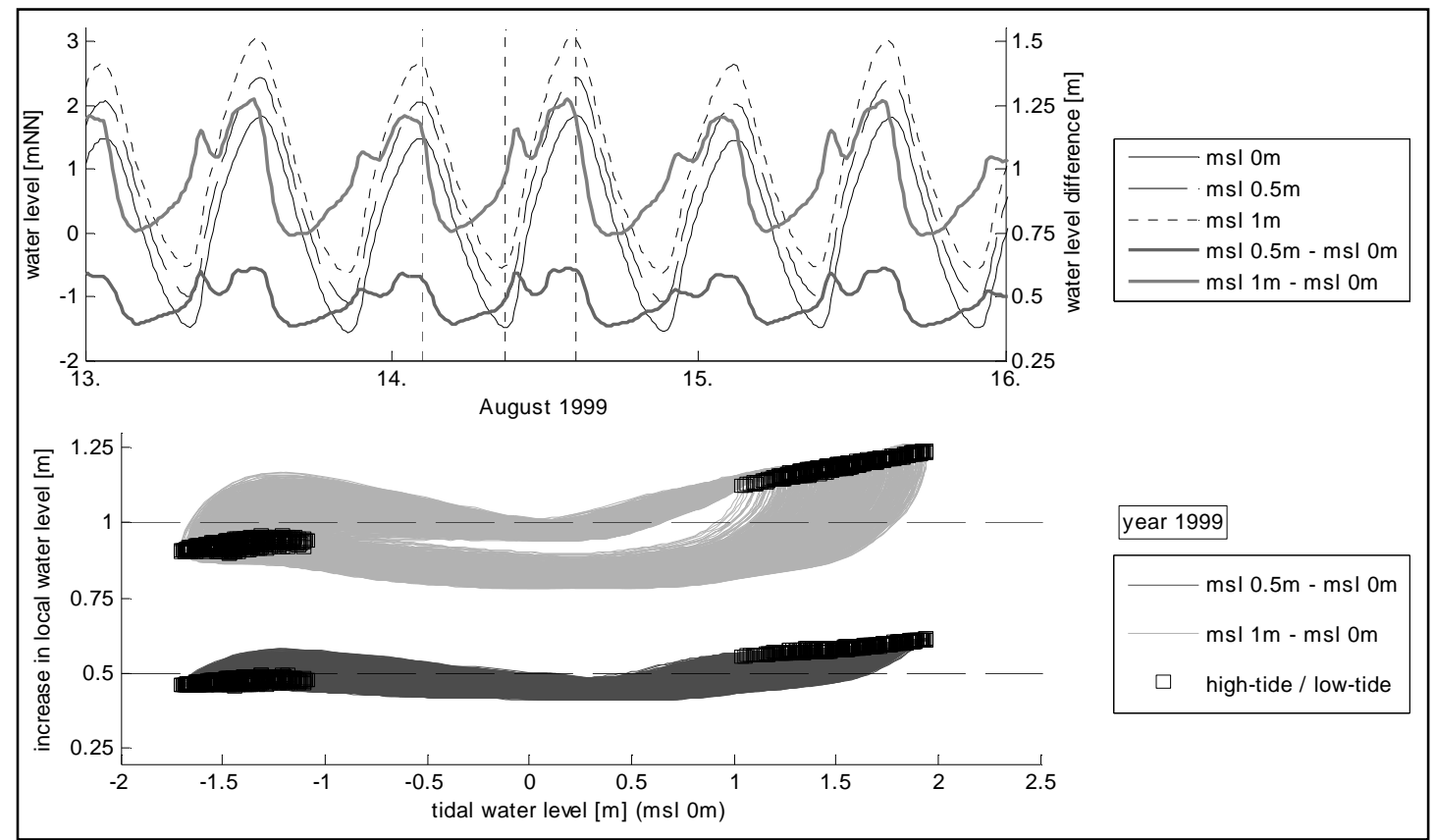

Fig. 5. Water levels at Cuxhaven of simulations with different MSL

\section{Storm surges}

To investigate the interactions between the tide and storm surges, the wind- and air pressure fields of the three storm events described above are temporally shifted and superimposed with the tide. Each of the storms is shifted to different positions within the representative tidal period of Aug. '99. Several shifts with an hourly increment were performed in such a way, that the temporal occurrences of the peaks of the surges cover the entire period of $\sim 14$ hours of the representative tide (Fig.6 top). The tide is generated in the NE-Atlantic model and passed as boundary conditions to the North Sea model where wind- and air pressure fields are imposed thus overlaying surge and tide.

The top of Fig. 6 shows the resulting surges in Cuxhaven exemplary for the storm of ' 67 . Each grey line represents the surge of one simulation, determined by subtracting the representative tide from the absolute water level of the superposition. The 14 storm surges in Fig. 6 differ in their peaks as well as in their shape (temporal development). This is observed for the other two storms as well. The main objective here is to determine the interaction between the maximum surge height and the tidal water level. To that end the maximum surge height at any time along the representative tide is determined as the upper envelope of all surges (black line Fig.6).

It should be mentioned, that if the peak of a 'standalone surge' is shifted to a certain time and overlaid with the tide, the resulting surge (after subtraction of the tide) might show the peak at a slightly different time. Another aspect of the 'upper envelope' is that the surge of a shift, being the highest surge at one time and constituting the point of the envelope at this time, might be even higher (but maybe not the highest), at another time. This does however not interfere with the following statements that are based on the analysis using the 'upper envelope' approach and is only mentioned to clarify the meaning of the 'upper envelope'. The 'upper envelope' is the highest possible surge at any time within the representative tidal period, produced by one storm occurring at any of the hourly temporal shifts.

The two lower panels of Fig. 6 show the upper envelopes of the surges of each of the three storms together with the tidal water level (y-axis on the right). In the middle panel the absolute values of the envelopes are plotted, in the lower panel all envelopes are normalized by their maximum. Again, as for an increased MSL, all three storm surges show a short but distinct increase at the beginning of the flood phase. Their interactions with the tide depend also on the tidal phase and not only on the absolute tidal water level. Generally, the surges are higher, if they occur close to low tide compared to high tide. The amount of reduction, when shifted from low tide to high tide is however variable between the three storms, suggesting a dependency on the type of the storm. 


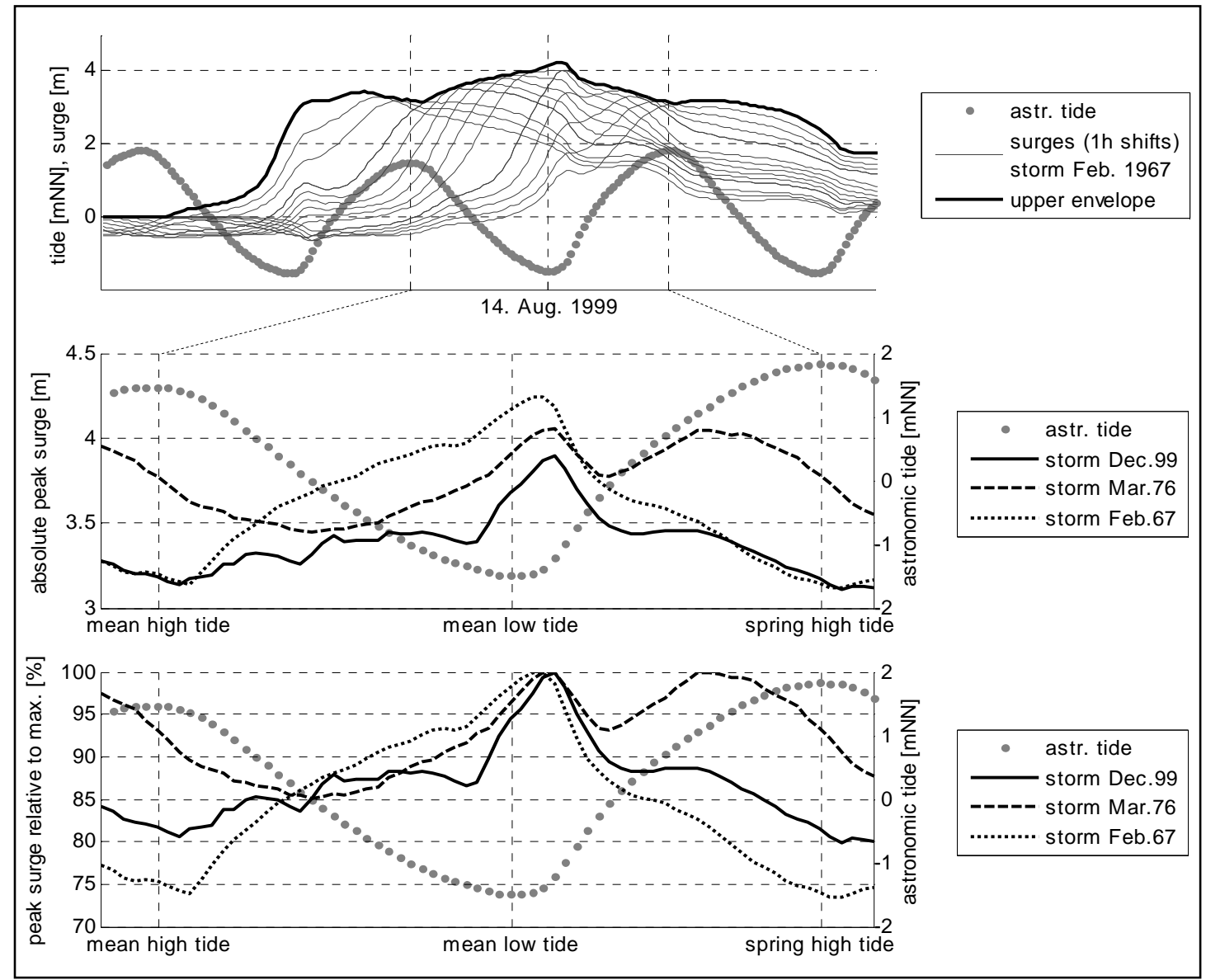

Fig. 6. Hourly shifts of the storm surge of 1967 relative to the tide of 14 . Aug. ' 99 (top). Maximum surge heights along the tide, absolute (middle) and relative to the maximum (bottom)

The reduction seems to be stronger for short storms ('67 and '99) and for high surges ('76). The comparatively long duration of the '76 storm (Fig.3) leads to the smallest variation of the interaction with the tide. The maximum of the surge is reached twice during the flood phase, at the beginning and close to the end, shortly before high tide.

\section{External surge}

For the selected external surge of Dec. '90 the same 14 hourly shifts as for the storms are performed within the period of the representative tide. The meteorological fields are applied over the NE-Atlantic superimposing external surges and tide. Within the North Sea no further transfer of momentum from the atmosphere is considered. Again the highest surge at any time along the representative tide is determined as upper envelope of all shifted surges. Fig. 7 shows the upper envelope of the external surge (solid black line), normalized by its maximum of around $0.9 \mathrm{~m}$. A short increase at the beginning of the flood phase is again visible. In contrast to the surges, produced by storms over the North Sea, the local effect of external surges is higher at high tide compared to low tide. The smallest external surge of only $70 \%$ of the maximum appears after a fast drop during the ebb phase.

\section{Summary of the individual interactions with the tide}

In Fig. 7 the highest effects (upper envelopes) of all processes are plotted together in normalized form. The two dotted lines of the effects of an increased MSL are the normalized differences of Fig. 5 within the period of the representative tide. The gray band represents the span of the effects of the three storms. Increased MSL and external surge show similar interactions with the tide. They lead to a higher increase of the local water level in Cuxhaven close to high tide. Storm surges lead to a higher increase close to low tide and their effect at high tide shows a large variation depending on the type of storm. 
Common to all interactions is the short but distinct increase of the effects at the beginning of the flood phase.

In the theory of stationary wind set up, the height of the wind set up is not only a function of the wind shear stress at the sea surface but also of the bottom roughness. The roughness is slowing down the near bottom back flow which is compensating the wind driven surface currents. A deceleration of the back flow supports the piling up of wind driven surges. According to this theory the wind set up is higher in shallow water where there is less space for backflow and the compensating current is affected stronger by the bottom roughness. This might partly explain the identified interaction patterns between storm surges and the tide. During the flood phase the tidal current is directed onshore and thus acting against the compensating current which leads to the increase of the wind set up. This is observed in all three storms. According to the stationary theory the offshore currents of the ebb phase reduce the wind surge by supporting the bottom close backflow. For the comparatively long and thus 'more stationary' surge of '76 this is observed (Fig. 6). The other two shorter storm surges do not show such a clear sensitivity to the ebb phase. This underlines the influence of the type of the storm. It is moreover interesting to notice, that the storm with the highest "standalone surge' ("67) is not the one leading to the highest absolute water level when superimposed with high tide (c.f. addition of surge and tide in middle panel of Fig. 6). The results suggest no uniform relation in the interactions between tide and storm surges, which cover any type of storm.

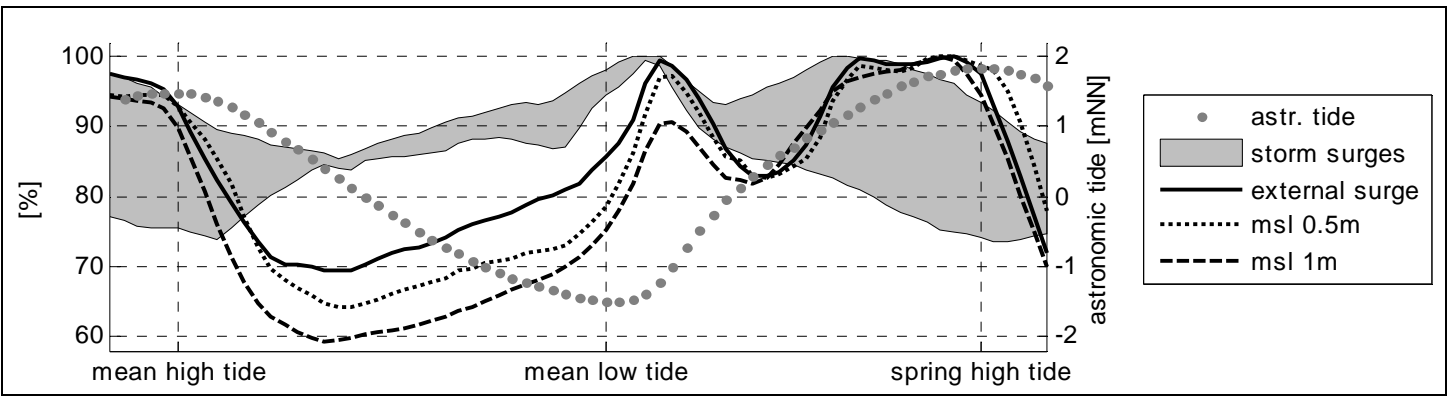

Fig. 7. Interactions of all processes with the tide

The theory for stationary wind set up does not apply for the other two processes of an increased MSL and external surges. In this processes there are no pronounced vertical circulation patterns. Still the interactions of these processes with the tide show an even stronger dependency on the tidal phase. In the case of an increased MSL the increase of the amplitude might be explained by the reduced effect of the bottom roughness. For higher water levels the retarding effect of the bottom roughness onto the tidal currents is reduced. The resulting higher tidal currents can transport a larger water volume and lead to a higher tidal amplitude near the coast. External surges of long period seem to interact similarly with the tide.

\section{INTERACTIONS BETWEEN PROCESSES}

To identify interactions not only with the tide but between all processes, different process combinations are simulated. External surge and tide are passed to the North Sea model in the form of boundary conditions and there overlaid with each of the three Storms. Due to the potentially large number of simulations the superpositions of different process combinations are performed only for the three representative tidal conditions of mean low tide, mean high tide and mean spring high tide out of the representative tidal period. The following combinations of processes are simulated:

- $T=$ Tide

- $T \_E=$ Tide + External surge

- $T \_S=$ Tide + Storm surge

- T_S_E = Tide + Storm surge + External surge

- T_msl = Tide msl $.5 \mathrm{~m}$

- T_msl_S = Tide msl .5m + Storm surge

- T_msl_E = Tide msl .5m + External surge

- T_msl_S_E = Tide msl .5m + Storm surge + External surge 
The simulations indicated in italic font are discussed above. The other superpositions are performed for each of the three storms with the peaks of storm- and external surges shifted to the three mentioned tidal conditions.

Individual components of the total water level, corresponding to the effects of each involved process, are determined by subtracting the water levels of different simulations. As an example, the component of the external surge $\mathrm{E}$ in the superposition of T_msl_S_E is determined as: $\mathrm{E}=\mathrm{T}$-msl_S_E - T_msl_S.

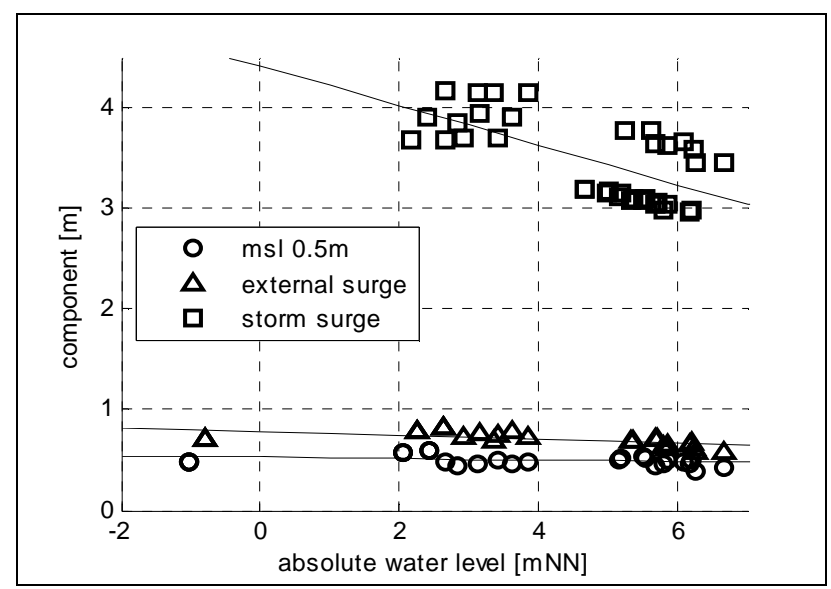

Fig. 8. Single process components of different superpositions in relation to the absolute water level.

In Fig. 8 all individual components are plotted against the absolute water levels of the corresponding superpositions. The different processes are distinguished by different symbols. The linear trends to the components of each of the processes suggest the tendency of a decreasing influence for an increasing absolute water level. The higher the absolute water level of the superposition the smaller the effects of each process. The amount of reduction seems moreover to be related to the magnitude of the components. The reduction of higher components (e.g. storm surge) is stronger.

In the above discussion of the interactions with the tide alone, it was observed, that the influences of an increased MSL and the external surge are higher at high tide. These components which are opposing the trend are included in the data of Fig. 8 and contribute to the scatter. The components of the storm surges show an even stronger scatter depending on the type of storm. The components considered here only represent the three tidal conditions of mean high tide, mean low tide and mean spring high tide. Above a peak of all effects was noted at the beginning of the flood phase. The scatter is therefore likely to increase even more, if other tidal conditions are included.

Another aspect worth mentioning is that the mathematical addition of all components (if $>2$ ) of one superposition usually deviates from the absolute water level of the superposition (e.g. $T+S+E \neq$ T_S_E). The amount of deviation is moreover variable which underlines the nonlinearity of the interactions.

\section{EXTREME SCENARIOS}

To arrive at scenarios of extreme water levels in Cuxhaven, the different contributions which have been modeled individually are superimposed in most adverse combinations. Storm and external surges are temporally shifted relative to the tide in such a way, that the peaks coincide with the spring high tide of 14. Aug. "99. The surges, that result from the overlay with the tide show their peak however at a slightly different time compared to the shifted 'standalone surges' (c.f. chapter storm surges). This is due to the nonlinearity of the interactions between the contributions and appears in the superposition of both, storm surge and external surge with the tide. Therefore the most adverse superpositions, leading to the highest water levels, are determined by iterative shifts and overlays. Simulations with and without an increase in the mean sea level are performed.

In the superposition of storms and external surges the meteorological fields of the storms over the North Sea are combined with the meteorological fields of the external surge over the NE-Atlantic. This implies an actual discontinuity in the meteorological situation along the boundary of the North Sea. The justification for the proposed method is however based on the assumption, that the existence of a 
consistent weather scenario, which leads to the coincidence of a high external surge and a strong storm surge in Cuxhaven, is possible (Gönnert et al., 2010a). The storm flood of February 1962, which had a devastating impact onto the German North Sea coast with more than 300 casualties, is such an example of the coincidence of storm and external surges.

\section{Comparison of extreme scenarios to observed events}

In Fig. 9 the extreme scenarios in terms of the most adverse superposition for each of the storms are compared to the original events. The water levels resulting from the superpositions of T_S, T_S_E and T_msl_S_E for a MSL of $0.5 \mathrm{~m}$ are plotted. The 'superposition scenarios' do not have a real time reference (e.g. storm surge of Fe. '67 and external surge of Dec. '90 are shifted to the tide in Nov. '99). To enable a better visual comparison, the peaks of the scenarios are therefore positioned at the time of the peak of the original event. It can be seen that the peak water levels of the scenarios are significantly increased compared to the original events.

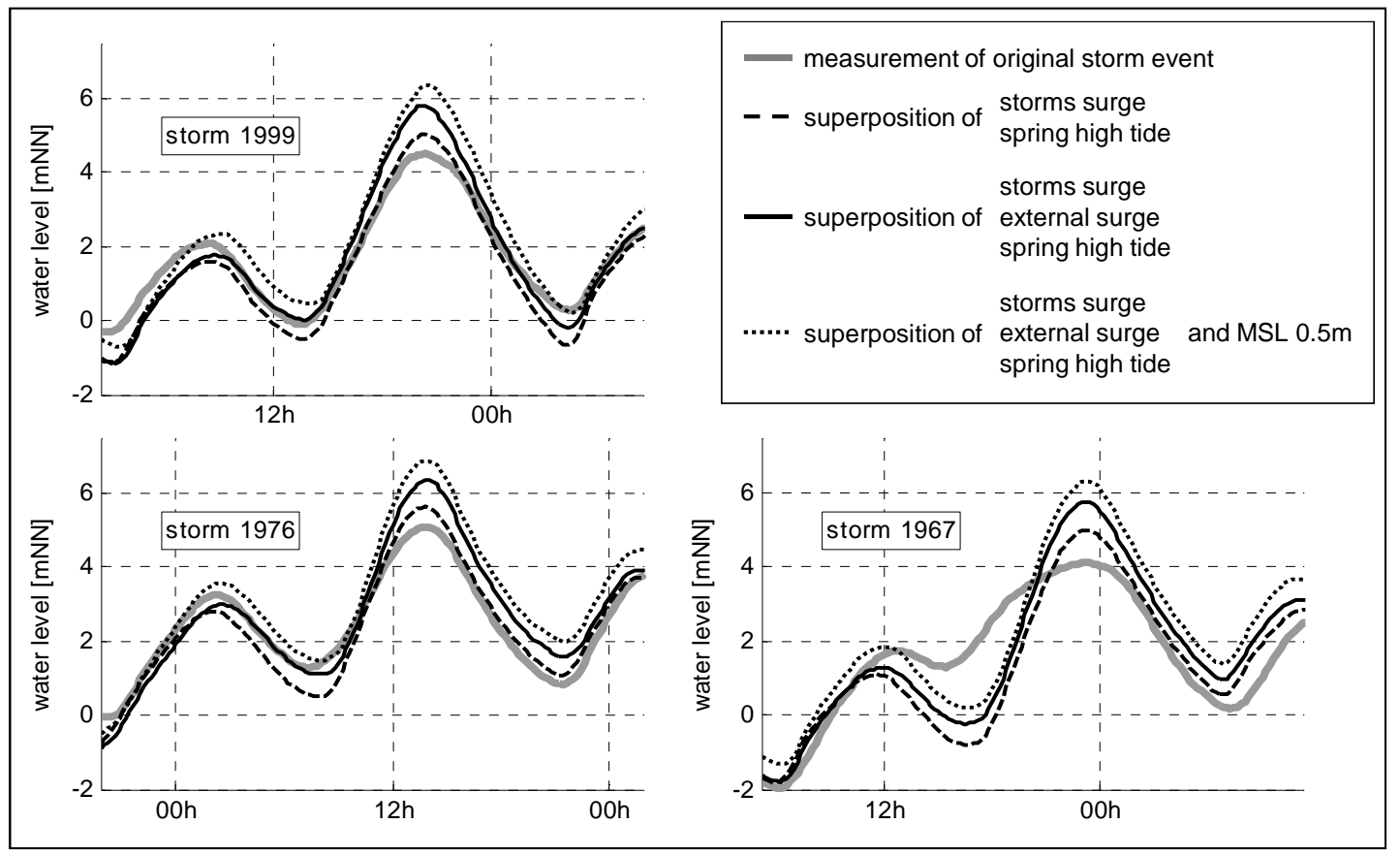

Fig. 9. New scenarios in comparison to the original events

According to the local storm surge classification of $\mathrm{BSH}$, events with water levels above $5 \mathrm{mNN}$ are considered in the highest category as 'very severe storm flood'. Of the original storms only the event of 1976 reaches a peak water level of $5.1 \mathrm{mNN}$. All new scenarios reach this class limit and all superpositions including the external surge exceeded it by at least $\sim 75 \mathrm{~cm}$. If the duration of one event is roughly defined as the time between the troughs before and after the peak, the durations of the new scenarios are similar to the original events. The time of exceedence of extreme water levels is however naturally different.

Out of the new scenarios the superposition of the storm surge of Jan. '76 with the external surge of Dec. '90 and the mean spring high tide of Nov. '90 leads to the highest water level in Cuxhaven. This shows, that it is not the storm of the highest 'standalone surge' of Feb. '67 which leads to the highest scenario when superimposed with the other processes. This is probably due to the distinctive interaction of the comparatively long storm surge of ' 76 with the tide. Despite the iterative maximization of the water level peaks to spring high tide, the actual highest water levels of the scenarios appear $\sim 30 \mathrm{~min}$ before spring high tide. This again is due to the nonlinear interactions between the processes. 


\section{CONCLUSIONS}

Process based numerical models have been used to investigate the superposition of different causes that lead to high water levels at the German North Sea coast. The following are the conclusions:

- Processes, that contribute to high water levels in Cuxhaven, like storm surges, external surges, tides and an increase in the MSL are decoupled and modeled individually. Each modeling technique is verified successfully.

- From the overlay of each process with the tide, it is found, that the tidal phase (flood or ebb) has a strong influence on the interactions. The effects of all processes show a short but distinct increase at the beginning of the flood phase. An increase in the MSL and the external surge lead to a higher increase of the local water level in Cuxhaven close to high tide. Storm surges lead to a higher increase close to low tide and their effect at high tide shows a large variation depending on the type of storm.

- The interactions of different process combinations are analyzed for the three tidal conditions of mean low tide, mean high tide and mean spring high tide. The results indicate that there is a relationship between the effects of each process and the absolute water level of the corresponding superposition. For higher absolute water levels the individual effects are generally reduced. This is in agreement with the results of empirical studies (Gönnert et al., 2010a \& b). Effects of higher magnitude, e.g. the components of storm surges, are furthermore reduced stronger. The scatter of the results is however large and no generally applicable relations for the process interactions can be derived.

- The proposed method of a model based decoupling of individual processes and their adverse superposition leads to new, consistent and extreme scenarios. The highest water level at Cuxhaven is simulated with the superposition of the mean spring high tide of 14. Aug. '99, the storm surge of the storm of Jan. '76 and the external surge of Dec. '90. It is not the highest recorded storm surge of Feb. '67, which leads to the most extreme scenario when superimposed with the other processes.

- Return periods for the scenarios are yet unknown and concerning the absolute values of the peak water levels, uncertainties in the boundary conditions have to be considered. Still all new scenarios fall within the highest local storm surge classification and might be used for various tasks of storm impact assessment.

New insights into the nonlinear interaction between tides, surges and an increase in the MSL have been gained. New questions arose from the results and further investigations are envisaged to improve the general understanding. A better knowledge about the involved processes might also help to support other fields of study like the development of stochastic storm surge models (Wahl et al., 2010), which in turn might be helpful in the determination of joint probabilities and return periods for the extreme scenarios described in this study.

\section{ACKNOWLEDGMENTS}

The Authors would like to acknowledge the Hamburg Agency of roads, bridges and waters, for the funding of this study. The Federal Maritime and Hydrographic Agency of Germany kindly provided the astronomical predictions for the station of Cuxhaven and the meteorological data from the MUSE project.

\section{REFERENCES}

Bork, I. und Müller-Navarra, S. 2006. Modellgestützte Untersuchungen zu Sturmfluten mit geringen Eintrittswahrscheinlichkeiten an der Deutschen Nordseeküste (MUSE), Teilbericht 2: Sturmflutsimulation. Abschlussbericht des KFKI-Forschungsvorhabens (03KISO39). In German.

Gönnert, G., 1999: The analysis of storm surge climate change along the German coast during the 20th century. Quaternary International, 56 (1999), 115-121.

Gönnert, G. 2003. Sturmfluten und Windstau in der Deutschen Bucht - Charakter, Veränderungen und Maximalwerte im 20. Jahrhundert. Die Küste. Archive for research and technology on the North Sea and Baltic coast. Heft 67, p.185-366. In German. 
Gönnert, G., Gerkensmeier, B., Müller, J.-M., Sossidi, K. und Thumm, S. 2010a. Zur hydrodynamischen Interaktion zwischen den Sturmflutkomponenten Windstau, Tide und Fernwelle. Zwischenbericht XtremeRisk, Teilprojekt 1a. In German.

Gönnert, G., Buß, Th. and Thumm, S. 2010b. Coastal Protection in Hamburg due to climate change. An example to design an extreme storm surge event. In: Proceedings of the First International Conference "Coastal Zone Management of River Deltas and Low Land Coastlines" (in print)

Jensen J. and Müller-Navarra S. 2008. Storm Surges on the German Coast. Die Küste. Archive for research and technology on the North Sea and Baltic coast. Heft 74, p.92-124.

Koziar, C., and Renner, V. 2005. Modellgestützte Untersuchungen zu Sturmfluten mit geringen Eintrittswahrscheinlichkeiten an der Deutschen Nordseeküste (MUSE), Teilbericht 1: Numerische Berechnung physikalisch konsistenter Wetterlagen mit Atmosphärenmodellen. Abschlussbericht des KFKI-Forschungsvorhabens (03KISO39). In German.

Lesser, G., Roelvink, J., van Kester, J., and Stelling, G. 2004. Development and validation of a threedimensional morphological model. Coastal Engineering, 51(8-9): 883-915.

Lüders, K. und Leis, G. (1964). Nds. Deichgesetz-Kommentar. Verl. Wasser u. Boden, Hamburg. In German.

Luthardt, H. 1987. Analyse der wassernahen Druck- und Windfelder über der Nordsee aus Routinebeobachtungen. Disseration, Universität Hamburg. Hamburger Geophys. Einzelschriften, Reihe A, Heft 83. In German.

Mayerle, R., Wilkens, J., Escobar, C. and Windupranata, W. 2005. Hydrodynamic Forcing Along the Open Sea Boundaries of Small-Scale Coastal Models. Die Küste. Archive for research and technology on the North Sea and Baltic coast. Heft 69, p.203-228.

Meehl, G.A., T.F. Stocker, W.D. Collins, P. Friedlingstein, A.T. Gaye, J.M. Gregory, A. Kitoh, R. Knutti, J.M. Murphy, A. Noda, S.C.B. Raper, I.G. Watterson, A.J. Weaver and Z.-C. Zhao, 2007. Global Climate Projections. In: Climate Change 2007: The Physical Science Basis. Contribution of Working Group I to the Fourth Assessment Report of the Intergovernmental Panel on Climate Change [Solomon, S., D. Qin, M. Manning, Z. Chen, M. Marquis, K.B. Averyt, M. Tignor and H.L. Miller (eds.)]. Cambridge University Press, Cambridge, United Kingdom and New York, NY, USA.

MLR-SH 2001. Generalplan Küstenschutz, Integriertes Küstenschutzmanagement in SchleswigHolstein. Ministerium für ländliche Räume des Landes Schleswig- Holstein. In German.

Müller-Navarra, S.H. and Giese, H. 1999. Improvements of an empirical model to forecast wind surge in the German Bight. Deutsche Hydrographische Zeitschrift, Jahrgang 51, 4, p. 385-405.

Mudersbach, Ch. and Jensen, J. (2006): Recent Sea Level Variation at the North Sea and Baltic Sea Coastlines, Proceedings of International Conference on Coastal Engineering (ICCE), Vol. 2, S. 1764-1774, World Scientific, San Diego, USA

Niemeyer, H.D. 2001. Bemessung von See- und Ästuardeichen in Niedersachsen. Die Küste. Archive for research and technology on the North Sea and Baltic coast. Heft 64, p.1-14. In German.

Rudolph, E. (2005): Einfluss sehr hoher Abflüsse auf die Wasserstände in der Tideelbe. promet 31 , p.186-190. In German.

Siefert, G. 1998. Bemessungswasserstände 2085A entlang der Elbe. Ergebnisse einer Überprüfung durch die Länderarbeitsgruppe nach 10 Jahren. Die Küste. Archive for research and technology on the North Sea and Baltic coast. Heft 60, p.228-255. In German.

Verboom, G., Ronde, J., and Dijk, R. (1992). A fine grid tidal flow and storm surge model of the North Sea. Continental Shelf Research (12 2/3), p. 213-233.

Wahl, T., Jensen, J. and Mudersbach, C. (2010): A multivariate statistical model for advanced storm surge analyses in the North Sea. Proceedings of the 32nd International Conference on Coastal Engineering, Shanghai, China, 2010. 